\title{
Sliding mode performance control applied to a DFIG system for a wind energy production
}

\author{
Mansouri Fatima Zohra, Bendjebbar Mokhtar, Mazari Benyounes \\ Laboratory of Development of Electrical Drives (LDEE), \\ University of Sciences and Technology Mohamed Boudiaf, Algeria
}

\begin{tabular}{l} 
Article Info \\
\hline Article history: \\
Received Jun 29, 2019 \\
Revised May 28, 2020 \\
Accepted Jun 9, 2020 \\
\hline Keywords: \\
Doubly fed induction generator \\
MPPT \\
PI controller \\
Sliding mode control \\
Wind energy conversion system
\end{tabular}

Article Info

Article history

Received Jun 29, 2019

Revised May 28, 2020

Accepted Jun 9, 2020

Wind energy conversion system

\begin{abstract}
This project presents a strategy of field control then sliding mode control put in to the conversion process of wind energy containing an asynchronous generator with double fed (DFAG; DFIG). A model was developed for each component of the wind turbine (turbine, DFAG and cascade rectifierinverter). MPPT device must be introduced in order to obtain maximum energy efficiency so that PI-MPPT method is made. The objective is to apply this command to control independently the active and reactive powers generated by the asynchronous generator uncoupled by orientation from the flow. The results of digital simulations obtained show the improvement of the performances of the sliding control compared to the field control, also it has provided information on the commands available techniques as reference tracking and robustness.
\end{abstract}

Copyright $\odot 2020$ Institute of Advanced Engineering and Science. All rights reserved.

\section{Corresponding Author:}

Mansouri Fatima Zohra,

Department of Electrical Engineering, Laboratory of Development of Electrical Drives (LDEE),

University of Science and Technology of Oran Mohamed Boudiaf El Mnaouar,

BP 1505, Bir El Djir 3100, Oran, Algeria.

Email: mansouri.fatimazohra@yahoo.fr

\section{INTRODUCTION}

Wind energy is one of the rapid growth renewable energy in the world. This energy is inexhaustible, clean and do not create greenhouse gases $[1,2]$. Conventional techniques were used to adjust the wind, but assuming the wind operation in balanced conditions [3]. Advances in technology of wind led to the design of a more powerful drive to improve their behaviors and make it more robust and reliable [4]. The generation of electrical energy by means of double-fed asynchronous machine is one of the current areas of research, using driving means such as wind power incorporated into a wind energy system, the function can DFIG on wide range of wind speed and get the maximum possible power for each wind speed [5].

In this article we demonstrate the modeling, the simulation and the comparison of the wind turbine driven doubly-fed induction generator performances of using at the same time the command of the PI control and sliding mode control $[6,7]$. A strategy for controlling the sliding mode has been put in place to control two powers and also achieve maximum wind energy $[8,9]$. The results of simulation show that this strategy has rapid dynamic response also a good robustness and low dependence parameters on the model [10].

\section{MODELING AND CONTROL OF THE WIND TURBINE}

The device, which is studied here, consists of a wind turbine including of the blades length $\mathrm{R}$ actuating a generator through a speed-increasing gear of profit G. Figure 1 describes a chain of conversion of wind energy $[5,11]$. 


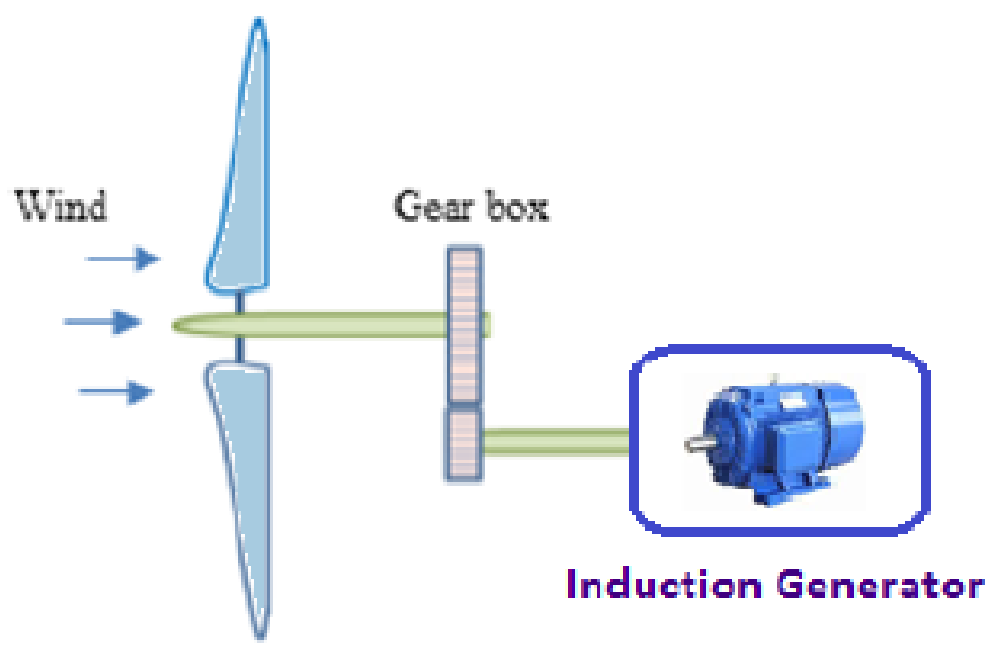

Figure1. Diagram of chain of energy transformation wind

\subsection{Model of the wind turbine}

Mechanical power available on the shaft of a wind turbine is expressed by $[6,7,12]$ :

$$
\begin{aligned}
& p_{\text {aer }}=\frac{1}{2} \cdot C_{p}(\lambda, \beta) \cdot \rho \cdot \pi \cdot R^{2} \cdot v^{3} \\
& \lambda=\frac{\Omega_{\text {turbine }} \cdot R}{G \cdot V}
\end{aligned}
$$

The torque of aerodynamic is directly determined by [1]:

$$
C_{a e r}=\frac{P_{a e r}}{\Omega_{\text {turbine }}}=\frac{1}{2} \rho C_{p} S v^{3} \frac{1}{\Omega_{\text {turbine }}}
$$

The mathematical modeling of the multiplier is given by the following equations:

$$
C_{g}=\frac{C_{a e r}}{G}
$$

and

$$
\Omega_{\text {turbine }}=\frac{\Omega_{m e c}}{G}
$$

The aerodynamic efficiency of the wind turbine is represented by the power factor $C_{p}(\lambda, \beta)$. The wind turbine is a complex model, however simple mathematical models are often used aerodynamic system. The expression of power coefficient that we will use in our study is given by $[3,13,14]$ :

$$
\begin{aligned}
& C_{p}(\lambda, \beta)=0.5176\left(116 \cdot \frac{1}{\lambda_{i}}-0.4 \cdot \beta-5\right) \cdot \exp \left(\frac{-21}{\lambda_{i}}\right)+0.0068 \lambda_{i} \\
& \frac{1}{\lambda_{i}}=\frac{1}{\lambda+0.08 \beta}-\frac{0.035}{\beta^{3}+1}
\end{aligned}
$$

The Figure 2 represent the characteristic of the power coefficient: 


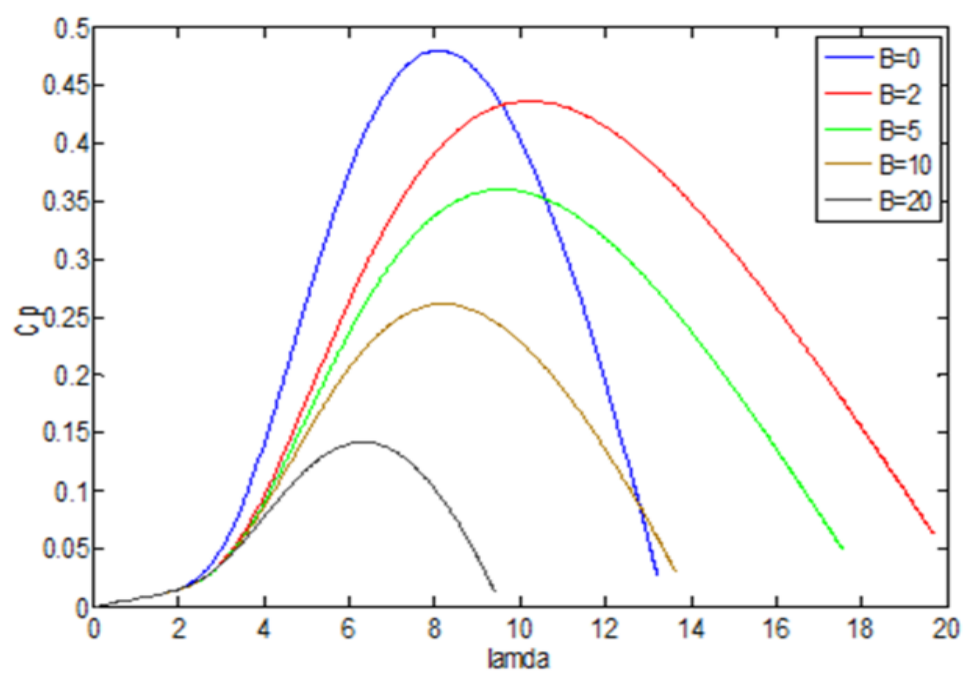

Figure 2. The characteristic of the power coefficient

We determine the evolution of the mechanical speed by the fundamental equation of dynamics [6]:

$$
\begin{aligned}
& C_{\text {mec }}=J \cdot \frac{d \Omega_{m e c}}{d t} \\
& C_{m e c}=C_{g}-C_{e m}-C_{v i s} \\
& C_{v i s}=f \Omega_{m e c} \\
& J=\frac{J_{\text {turbine }}}{G^{2}}+J_{g} \\
& f=\frac{f_{\text {turbine }}}{G^{2}}+f_{g}
\end{aligned}
$$

The diagram block related to this modeling of the turbine is represented on Figure 3.

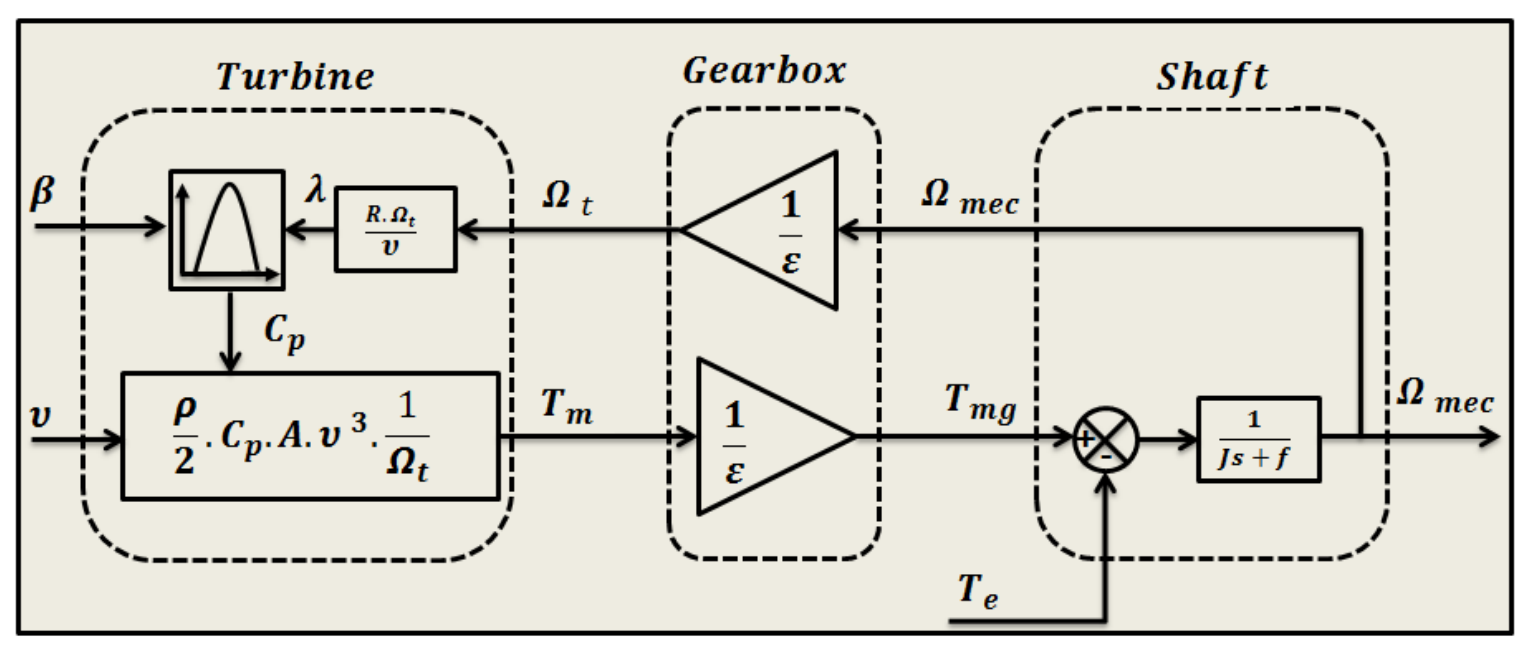

Figure 3. Block diagram of the model turbine 


\subsection{Control of the wind turbine}

An electromagnetic torque control strategy adjusting to the mechanical speed to be presented in this part in order to maximize the electrical power generated [15-18]. This principle is known as terminology (MPPT). We are interested in controlling the electromagnetic torque servo mechanical speed using a conventional PI controller [19]. For this study, we assume that the electric machine and its drive are ideal and therefore, the electromagnetic torque develops at all times equal to its reference value, regardless of the power generated. For this study, we assume that the electric machine and its drive are ideal and therefore, the electromagnetic torque develops at all times equal to its reference value, regardless of the power generated. The maximum power extraction techniques include determining the speed of the turbine, which provides maximum power generated $[17,18]$.

$$
\frac{d \Omega_{m e c}}{d t}=\frac{1}{J} \cdot\left(C_{g}-C_{e m}-f . \Omega_{m e c}\right)
$$

The structure of control consists in regulating the couple appearing on the turbine shaft so as to fix its speed at a reference. Therefore, we obtain the following relation [5]:

$$
\begin{aligned}
& C_{\text {emref }}=(K p+K i / p) \cdot\left(\Omega_{r e f}-\Omega_{\text {mec }}\right) \\
& \Omega_{\text {ref }}=G \cdot\left(\Omega_{\text {turbine-ref }}\right) \\
& \Omega_{\text {turbine-ref }}=\frac{\lambda \cdot C_{p \max } \cdot V}{R}
\end{aligned}
$$

\section{MODEL OF DFIG}

The double fed asynchronous generator DFIG is modeled in the reference mark of park, under its equations [3] and are represented by the Figure 4.

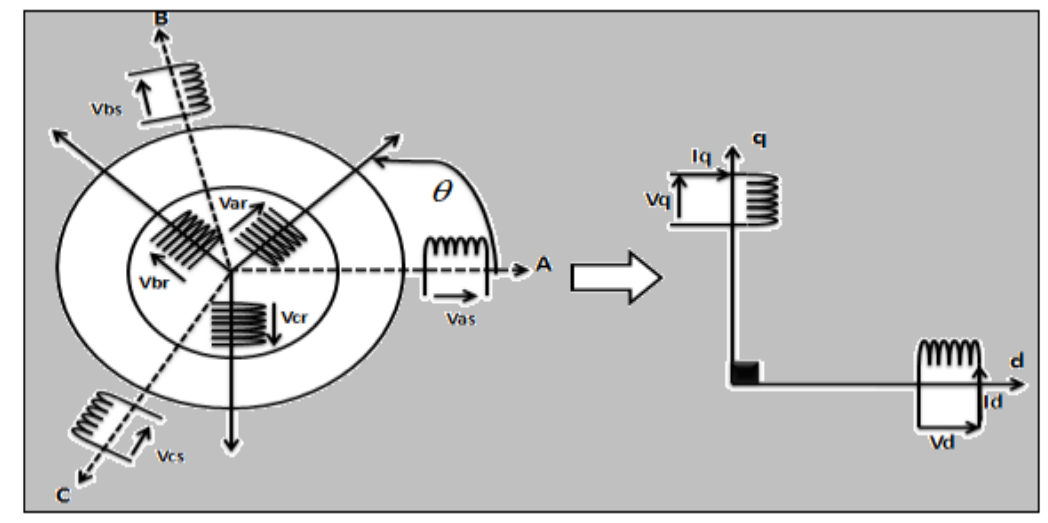

Figure 4. Park's transformation and two reference model of the DFIG

$$
\left\{\begin{array}{l}
V_{d s}=R_{s} I_{d s}+\frac{d \varphi_{d s}}{d t}-\dot{\theta}_{s} \varphi_{q s} \\
V_{d r}=R_{r} I_{d r}+\frac{d \varphi_{d r}}{d t}-\dot{\theta}_{r} \varphi_{q r} \\
V_{q s}=R_{s} I_{q s}+\frac{d \varphi_{q s}}{d t}-\dot{\theta}_{s} \varphi_{d s} \\
V_{q r}=R_{r} I_{q r}+\frac{d \varphi_{r}}{d t}-\dot{\theta}_{r} \varphi_{d r}
\end{array}\right.
$$




$$
\begin{gathered}
\left\{\begin{array}{c}
\varphi_{d s}=L_{s} I_{d s}+M I_{d r} \\
\varphi_{q s}=L_{s} I_{q s}+M I_{q r} \\
\varphi_{d r}=L_{r} I_{q r}+M I_{d s} \\
\varphi_{q r}=L_{r} I_{q r}+M I_{q s}
\end{array}\right. \\
C_{e m}=C_{r}+f \Omega+j \frac{d \Omega}{d t}
\end{gathered}
$$

Electromagnetic torque is expressed in terms of currents and flux:

$$
C_{e m}=P \frac{M}{L_{s}}\left(\varphi_{d s} I_{q r}-\varphi_{q s} I_{d r}\right)
$$

\subsection{Power control}

By putting the equations which connect the values, we can easily control the production of the wind and also realize an independent control of the active and reactive power [20]. A referential d-q; related to the rotating field and a stator flow aligned on the axis were adopted, For obvious reasons of simplification. Therefore:

$$
\varphi_{d s}=\varphi_{s}, \varphi_{q s}=0
$$

The flow equations (19) are becoming:

$$
\begin{aligned}
& \varphi_{d s}=L_{s} I_{d s}+M I_{d r} \\
& 0=L_{s} I_{q s}+M I_{q r}
\end{aligned}
$$

Based on a few considerations, we obtain:

$$
\begin{aligned}
& V_{d s}=0, V_{q s}=V_{s} \text { et } \varphi_{s}=\frac{V_{s}}{\omega_{s}} \\
& I_{d s}=-\frac{M}{L_{s}} I_{d r}+\frac{\varphi_{s}}{L_{s}} \\
& I_{q s}=-\frac{M}{L_{s}} I_{q r}
\end{aligned}
$$

In the biphasic landmark, statoric powers of DFIG are written:

$$
\begin{aligned}
& P_{s}=V_{d s} I_{d s}+V_{q s} I_{q s} \\
& Q_{s}=V_{q s} I_{d s}+V_{d s} I_{q s}
\end{aligned}
$$

The adaptation of these equations gives simplifying assumptions:

$$
\begin{aligned}
& P_{s}=-V_{s} \frac{M}{L_{s}} I_{q r} \\
& Q_{s}=-V_{s} \frac{M}{L_{s}} I_{d r}+\frac{V_{s}^{2}}{L_{s} \omega_{s}}
\end{aligned}
$$


For controlling the generator, expressions are set, showing the relationship between current and rotor voltages which will apply to it.

$$
\begin{aligned}
& V_{d r}=R_{r} I_{d r}+\left(L_{r}-\frac{M^{2}}{L_{s}}\right) \frac{d I_{d r}}{d t}-g\left(L_{r}-\frac{M^{2}}{L_{s}}\right) \omega_{s} I_{q r} \\
& V_{q r}=R_{r} I_{q r}+\left(L_{r}-\frac{M^{2}}{L_{s}}\right) \frac{d I_{q r}}{d t}-g\left(L_{r}-\frac{M^{2}}{L_{s}}\right) \omega_{s} I_{d r}+g \frac{M V_{s}}{L_{s}} \\
& \sigma=\left(1-\frac{L_{m}^{2}}{L_{s} L_{r}}\right)
\end{aligned}
$$

It should be noted that the powers and tensions are linked by a transfer function of the first order. Due to the low value of the slip, it is possible to establish vector control because the influences of the couplings remain weak and the $\mathrm{d}$ and $\mathrm{q}$ axes can be ordered separately with their own regulators. The method used in the power control is to neglect the coupling terms and to set up an independent regulator in each axis to control the active and reactive power independently. This method is called the direct method because the power controllers directly control the rotor tensions [2]. The block diagram representation is shown on the Figure 5.

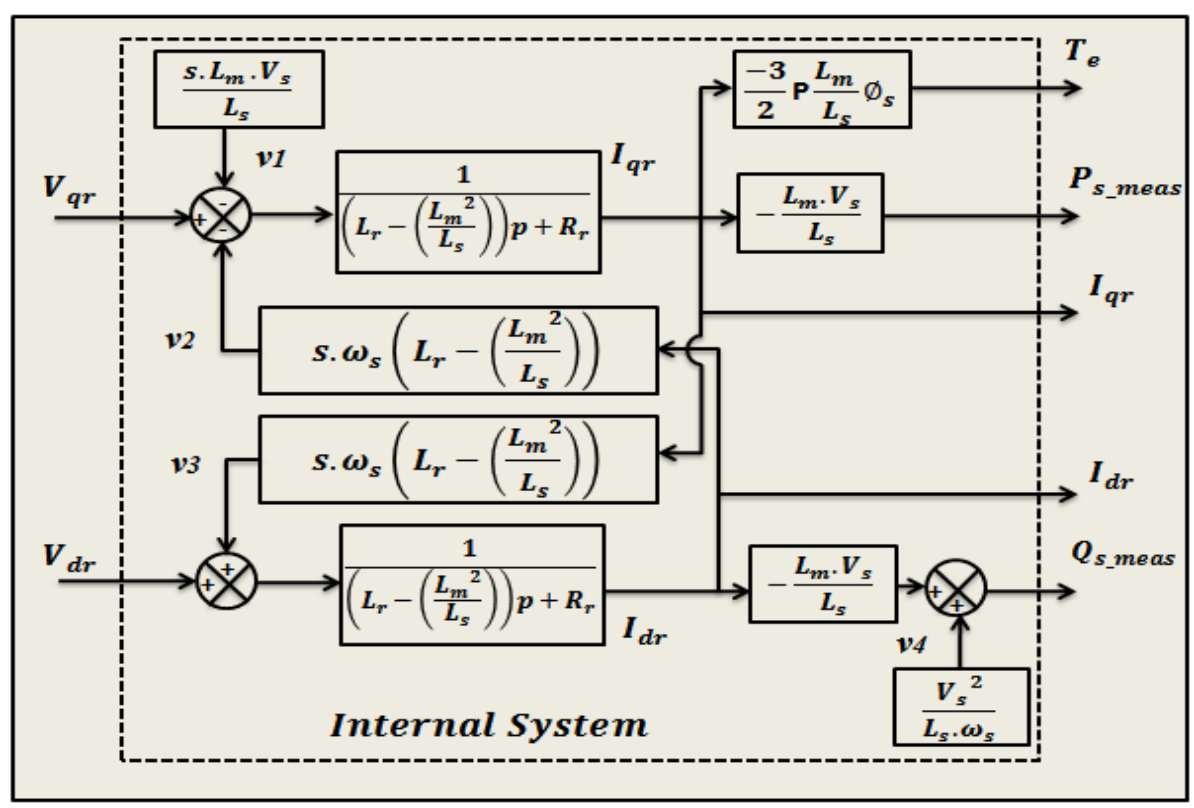

Figure 5. Control scheme of the system

\section{CONTROL ACTIVE AND REACTIVE POWERS}

This section as objective to introduce control algorithms based on two regulators PI and Sliding mode controllers to regulate a statoric powers to a DFIG system for a wind energy production [21-23].

\subsection{PI controller design}

The Figure 6 shows a closed loop system corrected by a PI regulator with a transfer function. The gains of the controllers are voluntarily chosen to be symmetrical, in order to preserve the property of symmetry of the open-loop:

$$
\left\{\begin{array}{l}
K_{p q}=K_{P P}=K_{P} \\
K_{i q}=K_{i p}=K_{i}
\end{array}\right.
$$


And the values of A and B are obtained from:

$$
\left\{\begin{array}{l}
A=L_{s} R_{r}+P\left(L_{r} L_{s}-L_{m}{ }^{2}\right) \\
B=L_{m} \cdot V
\end{array}\right.
$$

The transfer function of the open loop including the regulator is:

$$
G(P)=\frac{P+\frac{K_{i}}{K_{p}}}{\frac{P}{K_{p}}} \cdot \frac{\frac{L_{m} \cdot V_{s}}{\left(L_{r} L_{s}-L_{m}^{2}\right)}}{P+\frac{L_{s} R_{r}}{\left(L_{r} L_{s}-L_{m}^{2}\right)}}
$$

To cancel the pole, we added a zero at the same location as the pole, (40) gives a pole value.

$$
\frac{K_{i}}{K_{p}}=\frac{L_{s} R_{r}}{\left(L_{r} L_{s}-L_{m}^{2}\right)}
$$

The transfer function of the open loop becomes:

$$
G(P)=\frac{P+\frac{K_{i}}{K_{p}}}{\frac{P}{K_{p}}} \cdot \frac{\frac{L_{m} \cdot V_{s}}{\left(L_{r} L_{s}-L_{m}^{2}\right)}}{P+\frac{L_{s} R_{r}}{\left(L_{r} L_{s}-L_{m}^{2}\right)}}
$$

The closed loop is expressed by this function transfer:

$$
\begin{aligned}
& H(P)=\frac{1}{1+\tau_{r} P} \\
& \tau_{r}=\frac{1}{K_{p}} \cdot \frac{\left(L_{s} R_{r}-L_{m}^{2}\right)}{L_{m} V_{s}}
\end{aligned}
$$

For a response time $\tau_{\mathrm{r}}(5 \%)=10^{-3} \mathrm{~s}$ the $\mathrm{K}_{\mathrm{p}}$ and $\mathrm{K}_{\mathrm{i}}$ expressions were given by (42).

$$
\left\{\begin{array}{l}
K_{p}=K_{p q}=K_{P P}=\frac{1}{10^{-3}} \cdot \frac{\left(L_{s} R_{r}-L_{m}^{2}\right)}{L_{m} \cdot V_{s}} \\
K_{i}=K_{i q}=K_{i p}=\frac{1}{10^{-3}} \cdot \frac{L_{s} R_{r}}{L_{m} \cdot V_{s}}
\end{array}\right.
$$

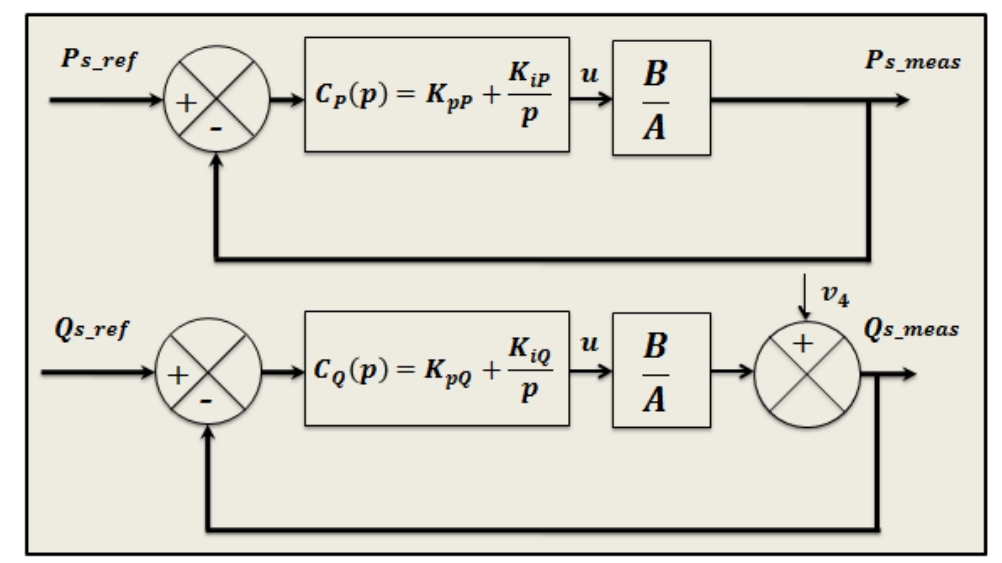

Figure 6. Equivalent PI control block 


\subsection{Sliding mode control}

The sliding Mode Control, is well known for its robustness against internal uncertainties (variations in machine parameters), and external (disturbance due to load), and phenomena having been omitted in the modeling, while having a very good response dynamic [24, 25]. In summary, a sliding mode control is divided into three parts.

\subsection{Control active power}

The surface of the control of the active power is given by:

$$
S(P)=P_{r e f}-P_{s}
$$

The derivative of surface is:

$$
S^{\bullet}(P)=P_{\text {sref }}^{\bullet}-P_{s}^{\bullet}
$$

We replace the expression of the power becomes:

$$
S^{\bullet}(P)=P_{\text {sref }}^{\bullet}-V_{s} \frac{M}{L_{s}} I_{q r}^{\bullet}
$$

We draw the expression from the current of the equation of the $\mathrm{V}_{\mathrm{qr}}$ tension:

$$
S^{\bullet}(P)=P_{\text {sref }}^{\bullet}-V_{s} \frac{M}{L_{s} L_{r} \sigma}\left(V_{q r}-R_{r} I_{q r}\right)
$$

By replacing the expression of $\mathrm{Vqr}$ by $\mathrm{V}_{\mathrm{qreq}}+\mathrm{V}_{\mathrm{qr} n}$ the command appears clearly in the following equation:

$$
S^{\bullet}(P)=P^{\bullet}{ }_{\text {sref }}-V_{s} \frac{M}{L_{s} L_{r} \sigma}\left(\left(V_{q r e q}+V_{q r n}\right)-R_{r} I_{q r}\right)
$$

During the sliding mode and in permanent mode, we have

$$
S(P)=0 \dot{S}(P)=0 V_{q r n}=0
$$

We extract from the preceding equation the equivalent manipulated variable $\mathrm{V}_{\text {qreq }}$ that is written:

$$
V_{q r e q}=\frac{-P^{\bullet}(S)_{s r e f}\left(L_{s} L_{r} \sigma\right)}{M V_{s}}+R_{r} I_{q r}
$$

During the mode of convergence, so that the condition $S(P) S^{\bullet}(P) \leq 0$ that is to say checked one poses:

$$
S^{\bullet}(P)=\frac{-V_{s} M}{L_{s} L_{r} \sigma} V_{q r n}
$$

Consequently, the term of commutation is given by:

$$
V_{q r n}=K \cdot \operatorname{sign}(s)
$$

To check the stability condition of the system, the parameter $\mathrm{K}$ must be positive.

\subsection{Control of the reactive power}

The surface of control of reactive power is:

$$
S(Q)=Q_{r e f}-Q_{s}
$$


The derivative of surface is:

$$
S^{\bullet}(Q)=Q^{\bullet}{ }_{\text {sref }}-Q^{\bullet}
$$

We replace the expression of the power becomes:

$$
S^{\bullet}(Q)=Q^{\bullet}{ }_{s r e f}-V_{s} \frac{M}{L_{s}} I_{d r}^{\bullet}
$$

We draw the expression from the current of the equation of the $\mathrm{V}_{\mathrm{qr}}$ tension:

$$
S^{\bullet}(Q)=Q^{\bullet}{ }_{s r e f}+V_{s} \frac{M}{L_{s} L_{r} \sigma}\left(V_{d r}-R_{r} I_{d r}\right)
$$

By replacing the expression of $\mathrm{Vdr}$ by $\mathrm{V}_{\mathrm{dreq}}+\mathrm{V}_{\mathrm{dr} \mathrm{n}}$ :

$$
S^{\bullet}(Q)=Q_{\text {sref }}+V_{s} \frac{M}{L_{s} L_{r} \sigma}\left(\left(V_{d r e q}+V_{d r n}\right)-R_{r} I_{q r}\right)
$$

In permanent mode, we have:

$$
S(Q)=0 \dot{S}(Q)=0 V_{q r n}=0
$$

We extract from the preceding equation the equivalent manipulated variable $\mathrm{V}_{\text {qreq }}$ that is written:

$$
V_{\text {dreq }}=\frac{-Q^{\bullet}(S)_{\text {sref }}\left(L_{s} L_{r} \sigma\right)}{M V_{s}}+R_{r} I_{d r}
$$

During the mode of convergence, so that the condition $S(Q) S^{\bullet}(Q) \leq 0$ that is to say checked one poses:

$$
S^{\bullet}(Q)=\frac{-V_{s} M}{L_{s} L_{r} \sigma} V_{d r n}
$$

Consequently, the term of commutation is given by:

$$
V_{d r n}=K \operatorname{sign}(s)
$$

To verify the stability condition of the system, the parameter $\mathrm{K}$ must be positive.

The Figures 7 and 8 represent the block diagram of the control structure.

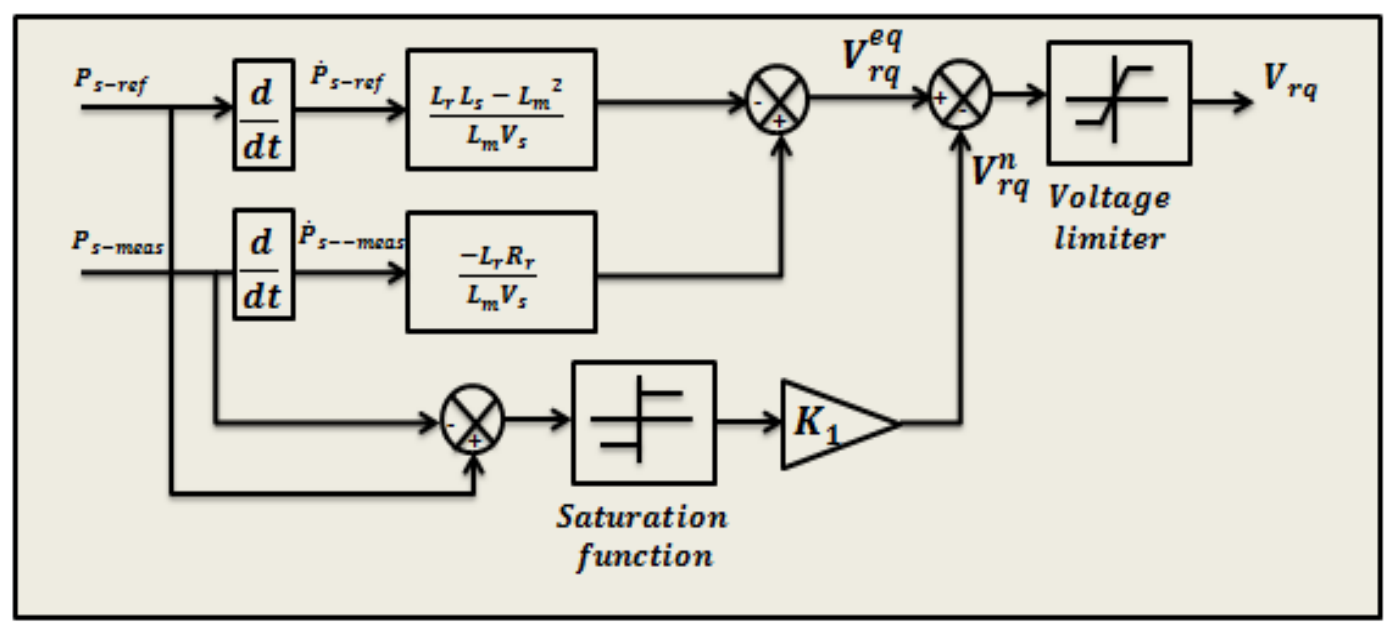

Figure 7. Sliding mode control structure for active power control 


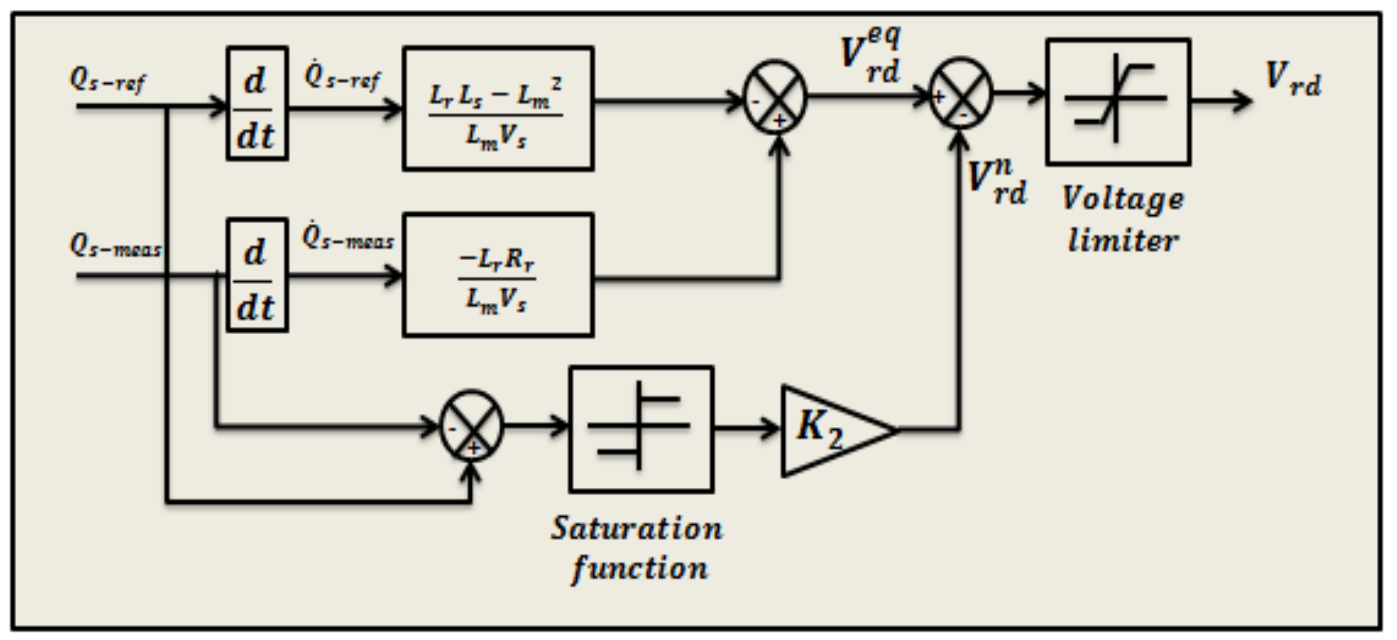

Figure 8. Sliding mode control structure for reactive power control

\section{RESULTS AND DISCUSSION}

In order to show and compare efficiently the two proposed controllers, a set of simulation tests have been carried using Matlab/Simulink. The both regulaters performances are tested and compared using two different specifications, the tracking of the references representing the robustness and the tracking based on changes of the system's parameters. The parameters of the wind turbine and DFIG are mentioned on the Table 1. Figure 9 shows the wind speed, Figure 10 shows the average output power as a function of wind speed.

Table1. Parameters of wind turbine and DFIG

\begin{tabular}{lll}
\hline Name & Symbol & Value \\
\hline Rated power & $\mathrm{P}$ & $1.5 \mathrm{MW}$ \\
The length of blade & $\mathrm{R}$ & $35.25 \mathrm{~m}$ \\
Rated wind speed & $\mathrm{V}_{\text {wrated }}$ & $12 \mathrm{~m} / \mathrm{s}$ \\
Rated stator voltage & $\mathrm{V}_{\mathrm{s}}$ & $690 \mathrm{~V}$ \\
Rated stator frequency & $\mathrm{F}$ & $50 \mathrm{~Hz}$ \\
Number of pole pairs & $\mathrm{p}_{\mathrm{n}}$ & $2 \mathrm{p.u}$ \\
Rotor winding resistance & $\mathrm{R}_{\mathrm{r}}$ & $0.19 \Omega$ \\
Stator winding inductance & $\mathrm{L}_{\mathrm{s}}$ & $0.084 \mathrm{H}$ \\
Rotor winding inductance & $\mathrm{L}_{\mathrm{r}}$ & $0.0213 \mathrm{H}$ \\
Magnetizing inductance & $\mathrm{L}_{\mathrm{m}}$ & $0.051 \mathrm{H}$ \\
Inertia of system & $\mathrm{J}$ & $1000 \mathrm{Kg} . \mathrm{m}^{2}$ \\
\hline
\end{tabular}

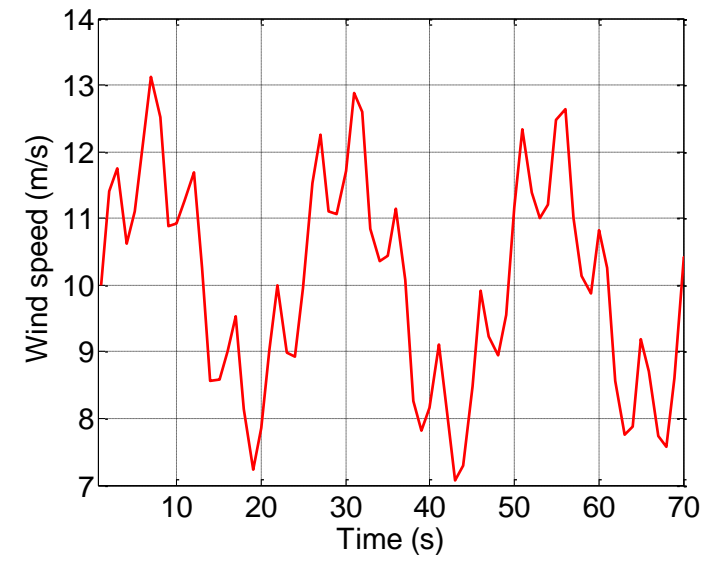

Figure 9. Variation of wind speed $(\mathrm{m} / \mathrm{s})$

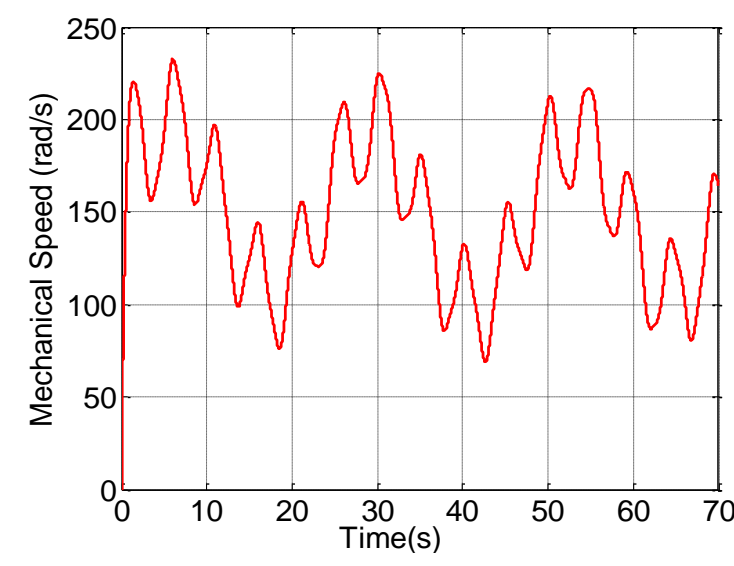

Figure 10. Speed of turbine 


\subsection{Reference tracking}

Different step inputs for an active and a reactive power were applied and we observed the response obtained with both PI control and Sliding mode control. Results are presented in the following Figures 11 and 12.

\subsection{Robustness}

In order to test the robustness of the two controllers, the nominal value of $\mathrm{Rr}$ is doubled value, and the value of mutual inductance Lm is decreased by $10 \%$ of its nominal value. Figures 13-16 shows the effect of parameters variation on the active and reactive power response for the two controllers.
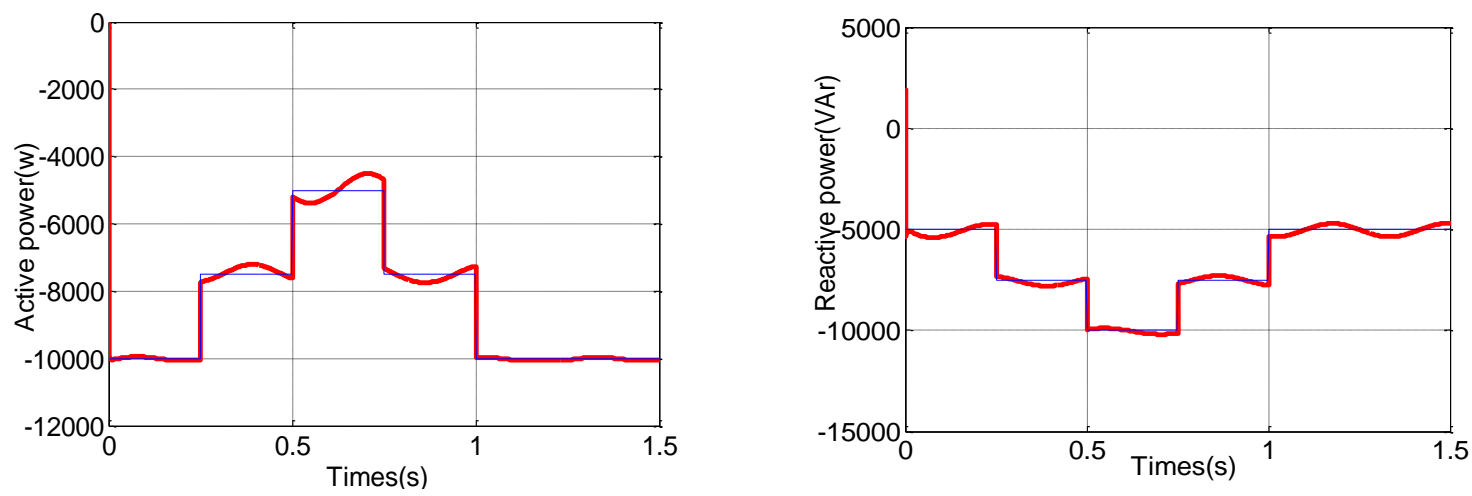

Figure 11. Dynamic responses of PI controller for a step change of active and reactive power
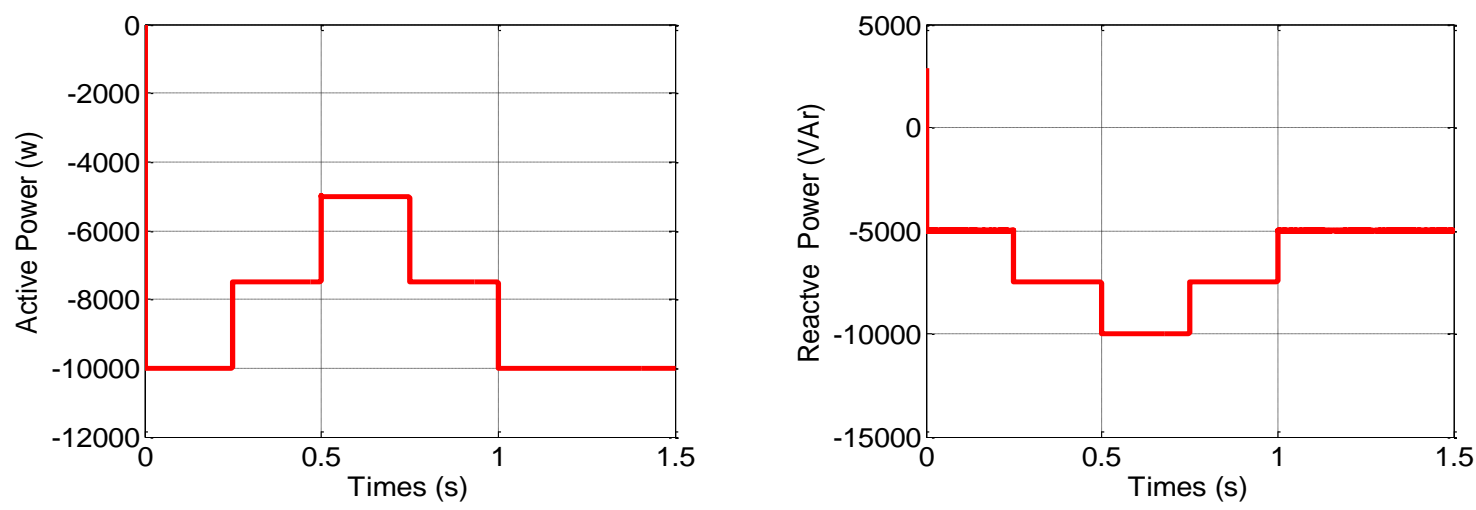

Figure 12. Dynamic responses of sliding mode control for a step change of active and reactive power
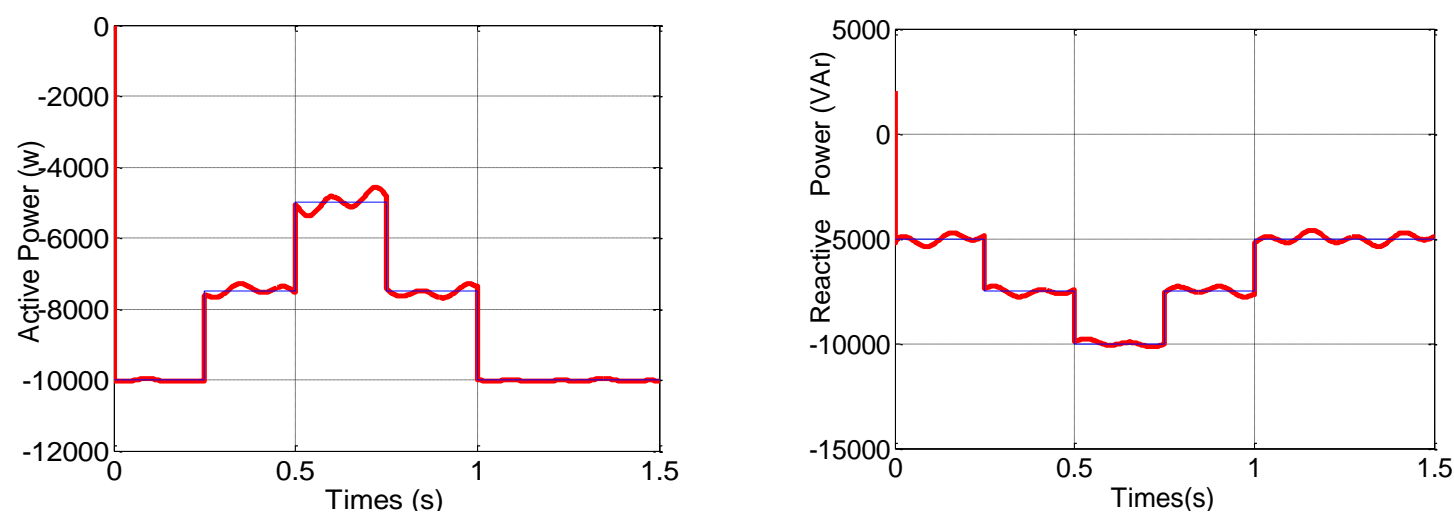

Figure 13. Active and reactive power behavior using PI controller with $50 \%$ variation of $\mathrm{Rr}$ 

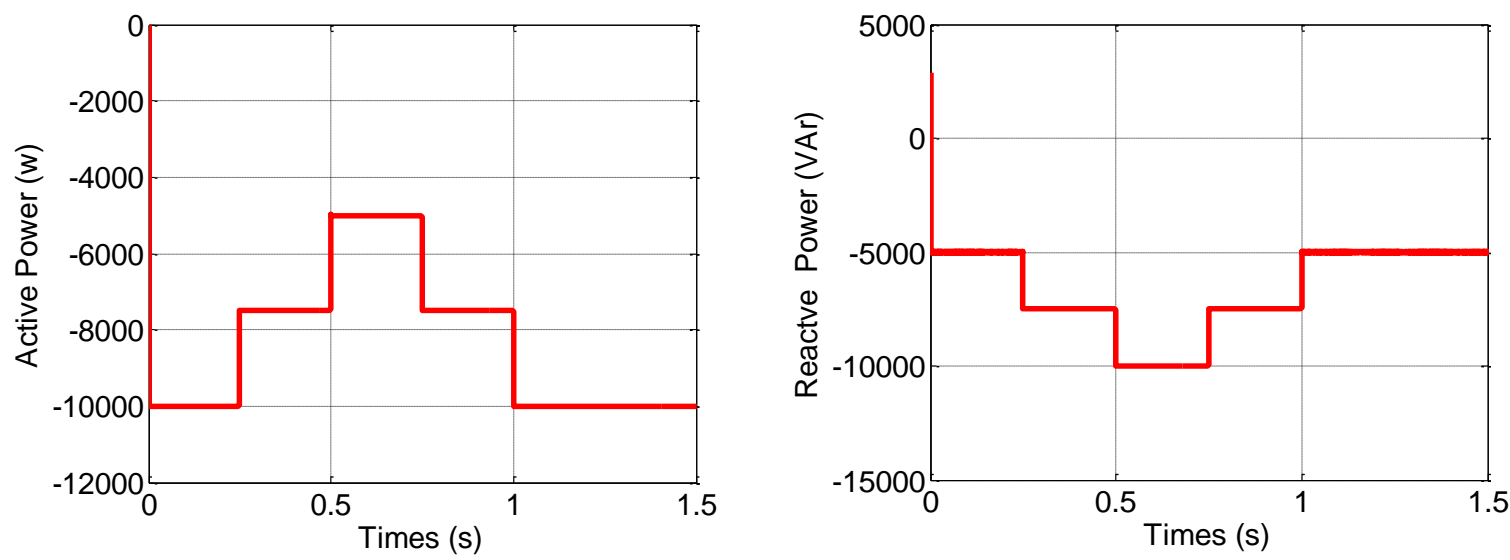

Figure 14. Active and reactive power behavior using Sliding Mode control with $50 \%$ variation of $\mathrm{Rr}$
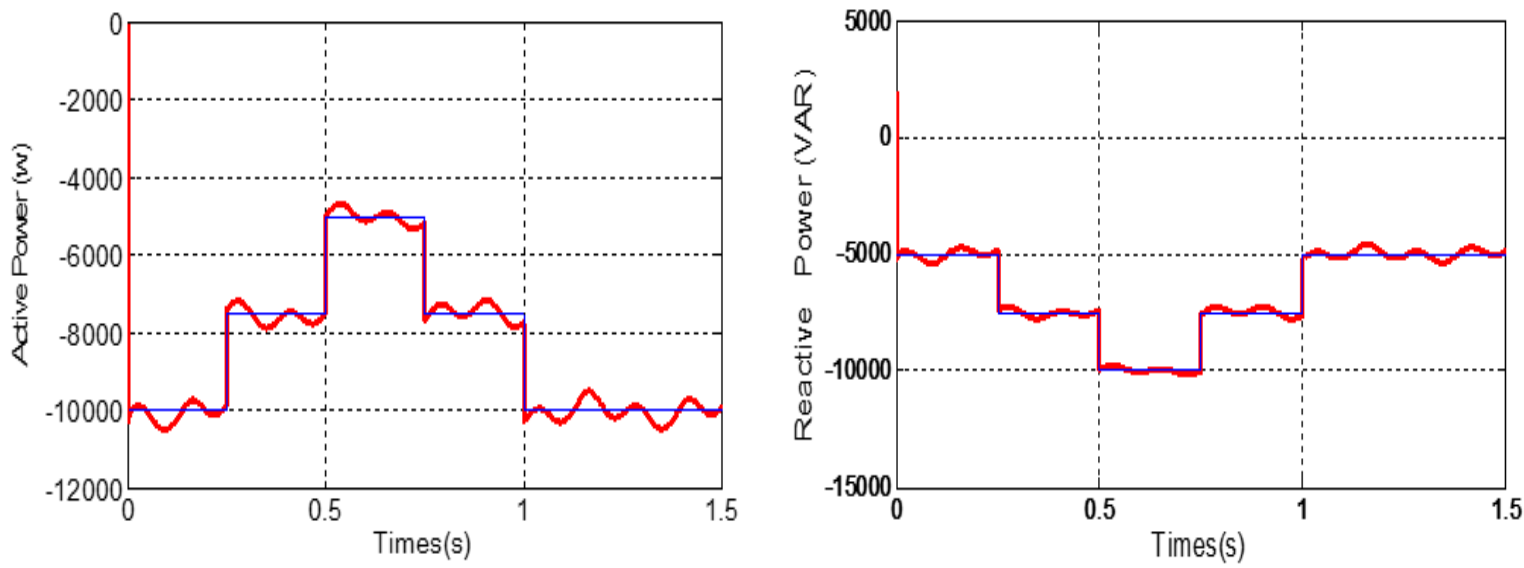

Figure 15. Active and reactive power behavior with Lm variation Using PI Controller
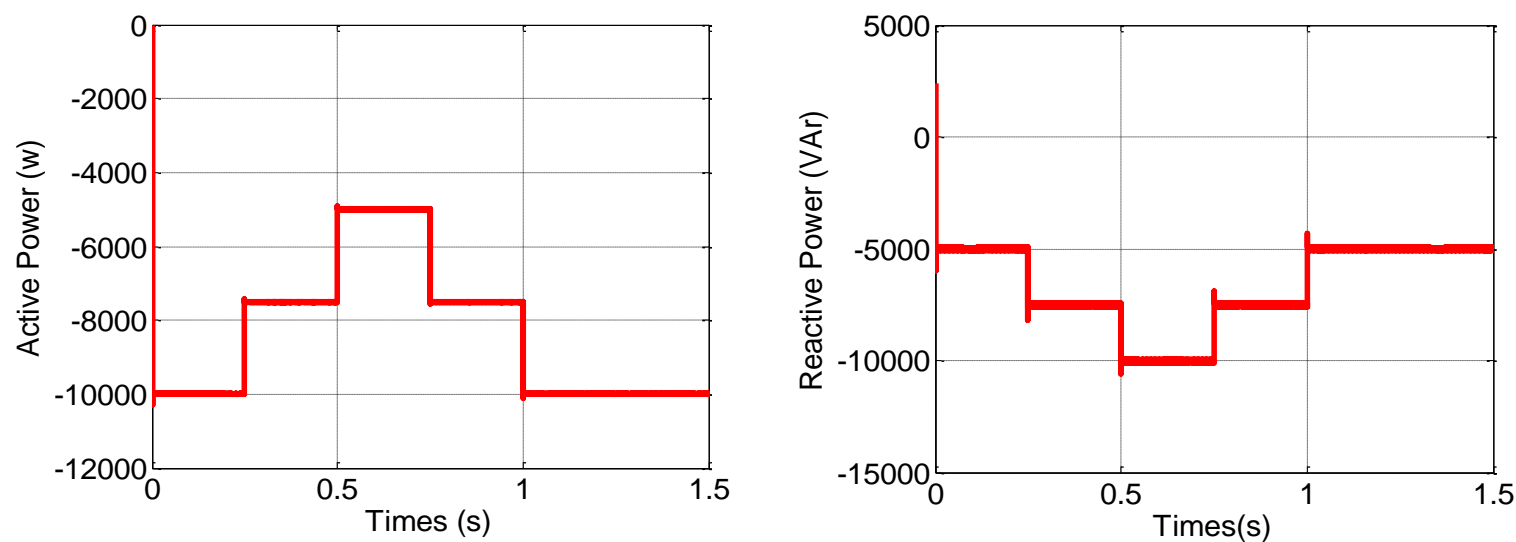

Figure 16. Active and reactive power behavior with $\mathrm{Lm}$ variation using sliding mode control

\subsection{Discussion}

With the sliding mode control the results show that the response time is considerably reduced, a small overshoot and the oscillations are damped more quickly compared to the PI controller. The system in transient state with the sliding mode is better than the PI control. 


\section{CONCLUSION}

This article presented a wind energy conversion system based on the wound rotor induction generator. Direct vector control of the active and reactive power of the stator was performed using Matlab/Simulink. The results shown illustrate that mathematical modeling based on knowledge of voltages and currents can be used to control powers. The comparative study of active and reactive power control reveals that the PI and Sliding Mode controllers work fairly well under ideal conditions when there is no disturbance or variation of parameters.

\section{REFERENCES}

[1] T. Ackermann and L. Soder, "An Overview of Wind Energy-Status 2002," Renewable and Sustainable Energy Reviews, vol. 6, no. (1-2), pp. 67-127, 2002.

[2] M. Allam, B. Dehiba, M. Abid, Y. Djeriri, and Redouane Adjoudj, "Etude comparative entre la commande vectorielle directe et indirecte de la Machine Asynchrone à Double Alimentation (MADA) dédiée à une application éolienne," Journal of Advanced Research in Science and Technology, vol. 1, no. 2, pp. 88-100, 2014.

[3] B. Wu, Y. Lang, N. Zargari, and S. Kouro, "Power conversion and control of wind energy systems," John Wiley \& Sons, Inc., United States of America, 2011.

[4] BM. Rapin, J-M. Noël, “Énergie Éolienne,” Dunod, Paris, 2010

[5] F. Poitiers, T. Bouaouiche, M. Machmoum, "Advanced control of a doubly-fed induction generator for wind energy conversion,” Electric Power Systems Research, vol. 79, no. 7, pp. 1085-1096, 2009.

[6] A. Boyette, "Contrôle-commande d'une GADA avec système de stockage pour la production éolienne," Thèse de Doctorat, Université Henry Poincaré, Nancy I, France, 2006.

[7] H-S. Ko, G-G. Yoon, N-H. Kyung, W-P. Hong, "Modeling and control of DFIG-based variable-speed windturbine," Electric Power Systems Research, vol. 78, no. 11, pp. 1841-1849, 2008.

[8] M. Taoussi, et al., "Comparative study between Backstepping adaptive and Field-oriented control of the DFIG applied to wind turbines," International Conference on Advanced Technologies for Signal and Image Processing, pp. 1-6, 2017.

[9] S-El-M. Ardjoun, M. Abid, A-G. Aissaoui, and A.Naceri, "A robust fuzzy sliding mode control applied to the double fed induction machine," International Journal Of Circuits, Systems and signals, vol. 5, no. 4, pp. 315-321, 2011

[10] P. Lopez and A. S. Nouri, "Théorie Elémentaire Et Pratique De La Commande Par Les Régimes Glissants," Springer Science \& Business Media, vol. 55, 2006.

[11] S. Mensou, A. Essadki, I. Minka, T. Nasser and B. Idrissi, "Backstepping Controller for a Variable Wind Speed Energy Conversion System Based on a DFIG," IEEE International Renewable and Sustainable Energy Conference (IRSEC), pp. 1-6, 2017.

[12] H. Alami, E. Ziani, B. Bossoufi, "Speed control of the doubly fed induction generator applied to a wind system," Journal of Theoretical and Applied Information Technology, vol. 83 no. 3, pp. 426-433, 2016.

[13] Hamane, B., Doumbia, M. L., Cheriti, A., Belmokhtar, K., "Comparative Study of PI, RST, Sliding Mode and Fuzzy Supervisory Controllers for DFIG based Wind Energy Conversion System," International journal of renewable energy, vol. 5, no. 4, pp. 1174-1185, 2015

[14] F. Kendouli, K. Nabti, K. Abed, and H. Benalla, "Modélisation, simulation et contrôle d'une turbine éolienne à vitesse variable basée sur la génératrice asynchrone à double alimentation," Revue des Energies Renouvelables, vol. 14, no. 1, pp. 109-120, 2011.

[15] F. Qiang, and T. Nan "A Strategy research on MPPT technique in photovoltaic power generation system," TELKOMNIKA Indonesian Journal of Electrical Engineering, vol. 11, no.12, pp. 7627-7633, 2013.

[16] M. Yuhendri, M. Ashari, and MH. Purnomo, "Maximum Output Power Tracking of Wind Turbine Using Intelligent Control," TELKOMNIKA Indonesian Journal of Electrical Engineering, vol. 9, no. 2, pp. 217-226, 2011.

[17] D. C. Phan DC and S. Yamamoto, "Maximum Energy Output of a DFIG Wind Turbine Using an Improved MPPTCurve Method," Energies, vol. 8, no. 10, pp. 11718-11736, 2015.

[18] D. Chung Phan and T. Hieu Trinh, "Maximum Power Extraction Method for Doubly-fed Induction Generator Wind Turbine," International Journal of Electrical and Computer Engineering (IJECE), vol. 8, no. 2, pp. 711-722, 2018.

[19] M. Nadour, A. Essadki, and T. Nasser, "Comparative Analysis between PI \& Backstepping Control Strategies of DFIG Driven by Wind Turbine," International Journal of Renewable Energy Research, vol. 7, no 3, pp. 1307-1316, 2017.

[20] Y. Ihedrane, C. El Bekkali, and B. Bossoufi, "Power Control of DFIG Generators for Wind Turbines Variable Speed," International Journal of Power Electronics and Drive Systems, vol. 8, no. 1, pp. 444-453, 2017.

[21] S. Mensou, A. Essadki, T. Nasser, B. B. Idrissi, "An Efficient Nonlinear Backstepping Controller Approach of a Wind Power Generation System Based on a DFIG," International Journal of Renewable Energy Research, vol. 7, no. 4 , pp. 1520-1528, 2017.

[22] I. Minka, A. Essadki, S. Mensou, and T. Nasser, "Power Control of a DFIG Driving by Wind Turbine: Comparison Study Between ADRC and PI Controller," International Renewable and Sustainable Energy Conference (IRSEC), pp. 1-8, 2017.

[23] J. J. Slotine, "Adaptive Sliding controller synthesis for nonlinear systems," International Journal of Control, vol. 43, no. 6, pp 1631-1651, 1986. 
[24] Ardjoun S, Abid M, Aissaoui A, and Tahour A., "A Robust Sliding Mode Control Applied To The Double Fed Induction Machine," Istanbul University-Journal of Electrical \& Electronics Engineering, vol. 12, no. 1, pp. 1445-1451, 2012.

[25] G. Zoubir, B. Cheikh, A. Tayeb and B. belkacem, "Speed-Sensorless DFIG Wind Turbine for Power Optimization Using Fuzzy Sliding Mode Observer," International journal of renewable energy research, vol. 7, no. 2, pp. 613-621, 2017.

\section{BIOGRAPHIES OF AUTHORS}

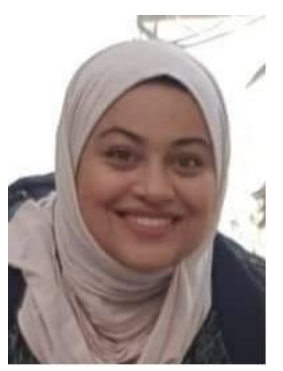

Mansouri Fatima Zohra was born in Oran, Algeria on March 09, 1989. She received the Engineer degree in Industriel Automated Systems from the University of Sciences and Technology of Oran M.B in 2011. She is member of laboratory development electrical drive (LDEE). Her research interests Renewable Energy, Sliding and Fuzzy Control.

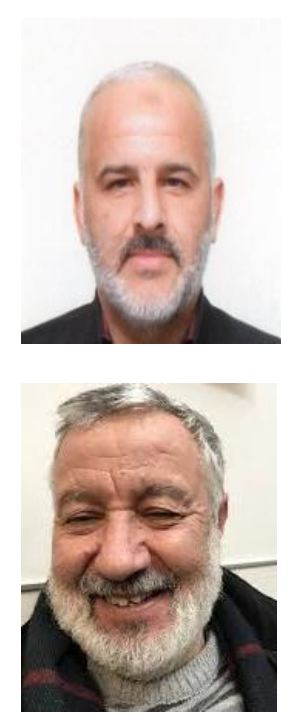

Mokhtar Bendjebbar was born on August, 16, 1965 in Relizane Algeria. He received received the B.S degree in electrical engineering and the M.S. and PhD degrees in electrical and control systems from the University of Sciences and Technology of Oran M.B., Algeria, in 1989, 1993, and 2007, respectively. He is currently Professor of Electrical Engineering at the University of Sciences and Technology of Oran. His research interests include Electrical machines and Drives Control, Power Electronics, as well as Intelligent Control and Diagnosis.

Mazari Benyounes (1953) received the state engineer degree in Electrical Engineering in 1978 from the University of Sciences and Technology of Oran (USTO) Algeria, the M.S. degree from the University of Colorado Boulder U.S.A. in 1981 and the doctorat degree from the Institut National Polytechnique de Lorraine (INPL) Nancy France in 1992. Since 1982, he was at the USTO-Oran and from 1987-1992 he was on leave as a researcher at INPL (France). Since 1992 he was a Professor of Electrical Sciences at the same university. His area of research includes power electronics, traction drives, and harmonics in power systems. 